\title{
CONSTRUCT INTEGRAL INEQUALITY FROM ALGEBRAIC INEQUALITY
}

Le Anh Tuan

Ha Noi University of Industry

\begin{abstract}
Integral inequality is part of the inequality. This is a difficult content. It attracts many mathematicians interested in, research and development. Integral inequalities are widely used in optimization problems, calculus, differential equations, integral equations, etc. In this paper, using the order-preserving property of the limit, we describe the construction of some integral inequalities from some known algebraic inequalities.
\end{abstract}

Keywords: Inequality; integral inequality; algebra inequality; integrable; limits.

Received: 24/02/2020; Revised: 27/02/2020; Published: 28/02/2020

\section{XÂY DỰNG BÂTT ĐẲNG THỨC TÍCH PHÂN TỪ BÂT ĐẲNG THỨC ĐẠI SỐ}

Lê Anh Tuấn

Truờng Đại học Công nghiệp Hà Nội

\section{TÓM TẮT}

Bất đẳng thức tích phân là một phần trong nội dung bất đẳng thức. Đây là một nội dung khó. Nó thu hút được nhiều nhà toán học quan tâm, nghiên cứu và phát triển. Bất đẳng thức tích phân được sử dụng nhiều trong các bài toán tối ưu, giải tích, phương trình vi phân, phương trình tích phân... Trong bài báo này, bằng việc sử dụng tính chất bảo tồn thứ tự của giới hạn, chúng tôi mô tả việc xây dựng một số bất đẳng thức tích phân từ một số bất đẳng thức đại số đã biết.

Từ khóa: bất đẳng thức; tích phân; đại số; khả tích; giới hạn.

Ngày nhận bài: 24/02/2020; Ngày hoàn thiện: 27/02/2020; Ngày đăng: 28/02/2020

Email: tuansl83@yahoo.com

https://doi.org/10.34238/tnu-jst.2020.02.2707 


\section{Method description}

In this section, we describe the method to construct integral inequalities from algebraic inequalities. We recall the definition of integrable function on closed interval $[a ; b]$.

Definition 1. Let $f(x)$ definite on $[a ; b]$. By a partition of $[a ; b]$, we mean a finite set of points $a=t_{0}<t_{1}<\cdots<t_{n}=b$. On each interval $\left[t_{i-1} ; t_{i}\right]$, we choose $x_{i}(i=1, \ldots, n)$. Let $\delta_{i}=t_{i}-t_{i-1}$. Put

$$
S=\sum_{i=1}^{n} f\left(x_{i}\right) \delta_{i}
$$

and $\Delta=\max \delta_{i}$. If the limits $\lim _{\Delta \rightarrow 0} S$ exits and indepent on all partitions of $[a ; b]$ and $x_{i}, f(x)$ is called integrable on $[a ; b]$. This limits is called integral of $f(x)$ on $[a ; b]$. Denote $\int_{a}^{b} f(x) d x$.

It is easy to see that if $f(x)$ is integrable on $[a ; b]$, we have

$$
\lim _{n \rightarrow \infty} \frac{b-a}{n} \sum_{i=1}^{n} f\left(x_{i}\right)=\int_{a}^{b} f(x) d x
$$

here $x_{i} \in\left[a+\frac{i-1}{n} ; a+\frac{i}{n}\right], i=1, \ldots, n$.

The method of constructing integral inequalities from known algebraic inequalities can be described as follows:

Assum that we have inequality

$$
P\left(\sum_{i=1}^{n} a_{i}, \sum_{i=1}^{n} b_{i}, \ldots\right) \geq 0 .
$$

Consider $a_{i}, b_{i}, \ldots$ as values of functions $f(x), g(x), \ldots$ at $x_{i} \in[a ; b]$.

We convert the inequality (2) into a form

$$
Q\left(\frac{b-a}{n} \sum_{i=1}^{n} a_{i}, \frac{b-a}{n} \sum_{i=1}^{n} b_{i}, \ldots\right) \geq 0 .
$$

Here $P, Q$ is continuos functions. By preserving order properties of limits and (1), we have inequality (3) transformed into

$$
Q\left(\int_{a}^{b} f(x) d x, \int_{a}^{b} g(x) d x, \ldots\right) \geq 0 .
$$

Now, we give some examples

Example 1. [1] Let $a_{1}, \ldots, a_{n}$ be positive real numbers. We have

$$
\left(a_{1}+\cdots+a_{n}\right)\left(\frac{1}{a_{1}}+\cdots+\frac{1}{a_{n}}\right) \geq n^{2} .
$$


Inequality (4) is equivalent to

$$
\left(\frac{b-a}{n} \sum_{i=1}^{n} a_{i}\right)\left(\frac{b-a}{n} \sum_{i=1}^{n} \frac{1}{a_{i}}\right) \geq(b-a)^{2} .
$$

If we consider $a_{i}$ as the values of integrable funtion $f(x)$, one have the following result.

Let $f(x)$ be positive and integrable on $[a ; b]$, then (see [2])

$$
\int_{a}^{b} f(x) d x \int_{a}^{b} \frac{d x}{f(x)} \geq(b-a)^{2} .
$$

Example 2 (Cauchy-Schwarz inequality). [1] Let $a_{1}, \cdots, a_{n}$ and $b_{1}, \cdots, b_{n}$ be real numbers. Then

$$
\sum_{i=1}^{n}\left|a_{i} b_{i}\right| \leq \sqrt{\sum_{i=1}^{n} a_{i}^{2}} \sqrt{\sum_{i=1}^{n} b_{i}^{2}}
$$

For $a<b$, inequality (5) equivalent to

$$
\frac{b-a}{n} \sum_{i=1}^{n}\left|a_{i} b_{i}\right| \leq \sqrt{\frac{b-a}{n} \sum_{i=1}^{n} a_{i}^{2}} \sqrt{\frac{b-a}{n} \sum_{i=1}^{n} b_{i}^{2}}
$$

Consider $a_{i}, b_{i}$ as the values of integrable funtions $f(x)$ and $g(x)$, we have.

If $f(x)$ and $g(x)$ are integrable on $[a ; b]$, then (see [2])

$$
\int_{a}^{b}|f(x) g(x)| d x \leq \sqrt{\int_{a}^{b} f^{2}(x) d x} \sqrt{\int_{a}^{b} g^{2}(x) d x .}
$$

\section{Some problems}

Problem 1. [1] Let $a_{1}, \cdots, a_{n}$ be positive real numbers. Then

$$
\sum_{i=1}^{n} a_{i} \sum_{i=1}^{n} \frac{1-a_{i}}{a_{i}} \leq n \sum_{i=1}^{n}\left(1-a_{i}\right) .
$$

Construct the corresponding integral inequality.

Solution. For $a<b$, inequality (6) equivalent to

$$
\left(\frac{b-a}{n} \sum_{i=1}^{n} a_{i}\right)\left(\frac{b-a}{n} \sum_{i=1}^{n} \frac{1-a_{i}}{a_{i}}\right) \leq \frac{b-a}{n}\left(\sum_{i=1}^{n}\left(1-a_{i}\right)\right) .
$$

Consider $a_{i}$ as the values of integrable funtion $f(x)$, we have the following result. Let $f(x)$ be positive and integrable on $[a ; b]$, then

$$
\int_{a}^{b} f(x) d x \int_{a}^{b} \frac{1-f(x)}{f(x)} d x \leq(b-a) \int_{a}^{b}(1-f(x)) d x .
$$


Problem 2. [4] Let $0<m \leq a_{i} \leq M$ for all $i=1, \ldots, n$, we have

$$
\left(\sum_{i=1}^{n} a_{i}\right)\left(\sum_{i=1}^{n} \frac{1}{a_{i}}\right) \leq \frac{n^{2}(M+m)^{2}}{4 M n}
$$

Construct the corresponding integral inequality.

Solution. Inequality (7) is equivalent to

$$
\left(\frac{b-a}{n} \sum_{i=1}^{n} a_{i}\right)\left(\frac{b-a}{n} \sum_{i=1}^{n} \frac{1}{a_{i}}\right) \leq(b-a)^{2} \frac{(M+m)^{2}}{4 M n} .
$$

Consider $a_{i}$ as the values of positive and integrable funtion $f(x)$, we have the following result.

If $f(x)$ is integrable on $[a ; b]$ such that $0<m \leq f(x) \leq M$, then (see [2])

$$
\int_{a}^{b} f(x) d x \int_{a}^{b} \frac{1}{f(x)} d x \leq(b-a)^{2} \frac{(M+m)^{2}}{4 M n}
$$

Problem 3 (Chebyshev inequality). [1] Let $a_{1}, \cdots, a_{n}$ and $b_{1}, \cdots, b_{n}$ be real numbers such that $a_{1} \leq \cdots \leq a_{n}$ and $b_{1} \leq \cdots \leq b_{n}$ (or $a_{1} \geq \cdots \geq a_{n}$ and $\left.b_{1} \geq \cdots \geq b_{n}\right)$, then

$$
\left(\sum_{i=1}^{n} a_{i}\right)\left(\sum_{i=1}^{n} b_{i}\right) \leq n \sum_{i=1}^{n} a_{i} b_{i} .
$$

Construct the corresponding integral inequality.

Solution. For $a<b$, the inequality (8) is equivalent to

$$
\left(\frac{b-a}{n} \sum_{i=1}^{n} a_{i}\right)\left(\frac{b-a}{n} \sum_{i=1}^{n} b_{i}\right) \leq \frac{(b-a)^{2}}{n} \sum_{i=1}^{n} a_{i} b_{i} .
$$

Consider $a_{i}$ and $b_{i}$ as values of funtions $f(x)$ and $g(x)$, we have the following result.

If $f(x)$ and $g(x)$ are either both increasing or both decreasing on $[a ; b]$, then (see $[2])$

$$
\int_{a}^{b} f(x) d x \int_{a}^{b} g(x) d x \leq(b-a) \int_{a}^{b} f(x) g(x) d x .
$$

Problem 4 (Hölder's inequality). [3] Let $a_{1}, \cdots, a_{n}$ and $b_{1}, \cdots, b_{n}$ be real numbers and $p, q>1$ such that $\frac{1}{p}+\frac{1}{q}=1$, then

$$
\sum_{i=1}^{n}\left|a_{i} b_{i}\right| \leq\left(\sum_{i=1}^{n}\left|a_{i}\right|^{p}\right)^{\frac{1}{p}}\left(\sum_{i=1}^{n}\left|b_{i}\right|^{q}\right)^{\frac{1}{q}}
$$

Construct the corresponding integral inequality. 
Solution. The inequality (10) is equivalent to

$$
\frac{b-a}{n} \sum_{i=1}^{n}\left|a_{i} b_{i}\right| \leq\left(\frac{b-a}{n} \sum_{i=1}^{n}\left|a_{i}\right|^{p}\right)^{\frac{1}{p}}\left(\frac{b-a}{n} \sum_{i=1}^{n}\left|b_{i}\right|^{q}\right)^{\frac{1}{q}}
$$

for $a<b$. We have the following result.

If functions $f(x), g(x)$ are integrable on $[a ; b]$ and $p, q>1$ such that $\frac{1}{p}+\frac{1}{q}=1$, then (see [2])

$$
\int_{a}^{b}|f(x) g(x)| d x \leq\left(\int_{a}^{b}|f(x)|^{p} d x\right)^{\frac{1}{p}}\left(\int_{a}^{b}|g(x)|^{q} d x\right)^{\frac{1}{q}} .
$$

Problem 5 (Minkowski inequality). [3]For $a_{1}, \cdots, a_{n}, b_{1}, \cdots, b_{n}$ are real numbers and $p>1$, then

$$
\left(\sum_{i=1}^{n}\left|a_{i}+b_{i}\right|^{p}\right)^{\frac{1}{p}} \leq\left(\sum_{i=1}^{n} a_{i}^{p}\right)^{\frac{1}{p}}+\left(\sum_{i=1}^{n} b_{i}^{p}\right)^{\frac{1}{p}}
$$

Construct the corresponding integral inequality.

Solution. The inequality (11) is equivalent to

$$
\left(\frac{b-a}{n} \sum_{i=1}^{n}\left|a_{i}+b_{i}\right|^{p}\right)^{\frac{1}{p}} \leq\left(\frac{b-a}{n} \sum_{i=1}^{n} a_{i}^{p}\right)^{\frac{1}{p}}+\left(\frac{b-a}{n} \sum_{i=1}^{n} b_{i}^{p}\right)^{\frac{1}{p}} .
$$

forall $a<b$. We have the following result.

If $f(x)$ and $g(x)$ integrable on $[a ; b]$ and $p>1$, then (see [2])

$$
\left(\int_{a}^{b}|f(x)+g(x)|^{p} d x\right)^{\frac{1}{p}} \leq\left(\int_{a}^{b}|f(x)|^{p} d x\right)^{\frac{1}{p}}+\left(\int_{a}^{b}|g(x)|^{p} d x\right)^{\frac{1}{p}} .
$$

Problem 6. [4] Let $a_{1}, \cdots, a_{n}, b_{1}, b_{n}$ are real numbers, $b_{i} \neq 0$ and $m \leq \frac{a_{i}}{b_{i}} \leq M$ for all $i=1, \cdots, n$, then

$$
\sum_{i=1}^{n} a_{i}^{2}+m M \sum_{i=1}^{n} b_{i}^{2} \leq(M+m) \sum_{i=1}^{n} a_{i} b_{i} .
$$

Construct the corresponding integral inequality.

Solution. For $a<b$, the inequality (12) is equivalent to

$$
\frac{b-a}{n} \sum_{i=1}^{n} a_{i}^{2}+m M \frac{b-a}{n} \sum_{i=1}^{n} b_{i}^{2} \leq(M+m) \frac{b-a}{n} \sum_{i=1}^{n} a_{i} b_{i} .
$$

We have the following result.

Let $f(x)$ and $g(x)$ be integrable functions on $[a ; b], g(x) \neq 0$ and $m \leq \frac{f(x)}{g(x)} \leq M$ for all $x \in[a ; b]$, then

$$
\int_{a}^{b} f^{2}(x) d x+M m \int_{a}^{b} g^{2}(x) d x \leq(M+m) \int_{a}^{b} f(x) g(x) d x .
$$


Problem 7 (Jensen's inequality). [3] If $\varphi(x)$ is a convex function on $[\alpha, \beta]$, then for $\alpha_{1}, \ldots, \alpha_{n} \in[\alpha ; \beta]$, we have

$$
\varphi\left(\frac{\alpha_{1}+\cdots+\alpha_{n}}{n}\right) \leq \frac{\varphi\left(\alpha_{1}\right)+\cdots+\varphi\left(\alpha_{n}\right)}{n}
$$

Construct the corresponding integral inequality.

Solution. For $a<b$, the inequality (13) is equivalent to

$$
\varphi\left(\frac{1}{b-a} \frac{b-a}{n} \sum_{i=1}^{n} \alpha_{i}\right) \leq \frac{1}{b-a} \frac{b-a}{n} \sum_{i=1}^{n} \varphi\left(\alpha_{i}\right) .
$$

Consider $\alpha_{i}$ as the values of integrable function $f(x)$ on $[a ; b]$. We have the following result.

Suppose that $f(x)$ integrable $[a ; b]$ and $m \leq f(x) \leq M$ for all $x \in[a ; b]$. If $\varphi$ is continuous and convex on $[m ; M]$, then (see [2])

$$
\varphi\left(\frac{1}{b-a} \int_{a}^{b} f(x) d x\right) \leq \frac{1}{b-a} \int_{a}^{b} \varphi(f(x)) d x .
$$

Summary: In this paper, by using order-preserving through limiting, we give the method to construct some integral inequalities from known algebraic inequalities.

\section{References}

[1]. W. J. Kaczor, M. T. Nowak, Problems in Mathematical Analysis I. Real Numbers, Sequences and Series. American Mathematical Society, Providence, RI, 2000.

[2]. W. J. Kaczor, M. T. Nowak, Problems in Mathematical Analysis III. Real Numbers, Integration. American Mathematical Society, Providence, RI, 2003.

[3]. W. J. Kaczor, M. T. Nowak, Problems in Mathematical Analysis II. Real Numbers, Continuty and Differentiation. American Mathematical Society, Providence, RI, 2001.

[4]. D. S. Mitrinovic, Analytic Inequalities. Springer-Verlag, 1970. 